\title{
Research on the Application of Computer Cloud Technology in Network Teaching
}

\author{
Rui Wang \\ Liaoning Jianzhu Vocational College, Liaoning, Liaoyang, 111000, China
}

\begin{abstract}
With the rapid development of computer technology, the construction of college education information is in full swing, computer technology and network communication technology have been widely used in college network teaching. The research of network teaching system based on cloud computing has become a new topic in the development of network teaching in colleges and universities. This paper makes a brief analysis of the characteristics and development of cloud computing technology, and studies the content and structure of the network teaching system based on cloud computing, and puts forward the design scheme of the network teaching system based on cloud computing.
\end{abstract}

Keywords: application, computer cloud technology, network teaching

\section{Introduction}

Computer cloud technology is a distributed computing technology, through the network will be a huge computational processing program automatically split into numerous smaller subroutines, and then by a number of servers consisting of a large system by the search, calculation and analysis. The result is then passed back to the user. Through this technology, network service providers can be reached in a few seconds to deal with tens of millions or even hundreds of millions of information, and supercomputers to achieve the same powerful performance of network services. In the rapid development of network technology and information technology today, computer cloud technology as a fast-growing new technology is bound to become a new direction for future development. Based on the great advantage of computer technology, education 
network has become a new form of modern education industry chase. Computer cloud technology in the development process, although they have encountered many problems, but in the practical application of modern open education process is still very competitive. This paper first describes the characteristics of cloud technology, analyzes the typical application of cloud computing technology in the education industry, discusses the problems in the application of modern open education, and then puts forward some opinions about cloud technology teaching.

\section{The brief description of cloud computing}

The domestic university teaching platform system is based on the computer technology as the core technology, and has been widely used in colleges and universities. Network teaching for teachers and students learning provides a new learning environment, in the construction of network teaching system, the school hardware and software infrastructure investment in a lot of money, given the computer hardware and software updates faster, colleges and universities in order to adapt to the development of computer hardware and software must be timely and hardware and software upgrades in the daily maintenance of the network teaching system should also spend a lot of manpower and material resources, so that brought the issue of funds to colleges and universities. Universities in the network teaching system platform integration, a number of network resources and hardware facilities to re-investment, this will result in a serious waste of resources. By the traditional teaching system platform, the network teaching system can not be shared between resources, affecting the construction of network teaching system. With the popularization of cloud computing technology, the construction of network teaching system of universities gradually adopts cloud computing technology, and cloud computing technology can realize the sharing of computer resources.

The traditional network teaching mode causes the information isolated island to share the teaching resources, so that the information resources can not be shared well among the subsystems, which brings the bottleneck to the resource sharing of the university network resource system and inconvenience to the users. Cloud computing has brought technology support to the development of network teaching resources in colleges and universities, and has satisfied the demand of college teachers and students for information technology services, which has become the focus of our education sector. Cloud computing technology is based on the Internet computer technology, cloud computing is the traditional computer technology and network technology integration, cloud computing in the traditional computer technology parallel computer, network storage and distribution computing. The goal of cloud computing is to provide virtual resource sharing over the Internet, which is calculated on a usage-by-use basis. Cloud computing provides on-demand network access to computer-shared resources, including server storage, application services and networking. Cloud computing can quickly improve the sharing of computer services, in the 
management of cloud computing do not need to invest too much effort. Cloud computing application services are rapidly developing, some foreign IT companies such as Intel and IBM is the most representative.

The centralized management of cloud computing allows enterprises to reduce costs while building and maintaining their data centres. Cloud computing is more resource-efficient and cost-effective than traditional system services. Cloud computing provides software services, platform services and infrastructure services, software services for the development of application-based cloud computing platform to develop an application framework, the platform service is an integrated application environment, the application development, servers, databases and other integrated, providing an intermediate platform for $\mathrm{R} \& \mathrm{D}$, infrastructure services to improve the environment for a software application, providing storage and virtual server services for users, infrastructure including hardware infrastructure and database resource pools. Cloud computing is the Internet in accordance with the requirements of users of infrastructure, software and platform integration of computer resources for rapid customization. User management is the management of the resources and services provided by cloud computing, cloud computing to ensure the safety and quality of computer resources and services.

\section{Research on network teaching based on cloud computing}

\subsection{The network teaching system design based on cloud computing}

The design of the network teaching system should be designed around the basic functions such as the production of the teaching courseware, the uploading of teaching materials, the online learning and answering, the download of the course resources and the online examination. Teachers and students, as well as student and student teaching resources between the information should be timely communication, so that teachers can effectively through the network of teaching. Network teaching system platform design teaching strategy, the establishment of online forum module and online Q \& A module as a learning strategy, students can provide courseware and other teaching resources for autonomous learning. The online test module is designed to evaluate the students' learning effect and to combine autonomous learning and assistant learning in the teaching process. In the design process of the teaching system, we should provide a platform for the teaching and learning of teachers and students. The design of the platform should be teacher-led and student-centred design principles, and cultivate students' ability of autonomous learning. The design of network teaching platform should be student-centred, to ensure that the platform function is simple and practical. The design of online examination and submission module should be convenient and quick. The design interface should be visualized and easy to maintain. The design platform is simple to operate. The design of the network teaching platform should have a number of management modules, the students' system management, teaching system management, curriculum management system 
integration together. Cloud computing network teaching system is a complex project, in the design of the time to have a complete set of strategies to ensure the limited capital investment, based on the establishment of an efficient network teaching platform system.

\subsection{The network teaching system structure design based cloud computing}

The network education system project development tool uses Windows visual studio2008, the backstage database uses SQL server 2008 edition, uses the B / S (browser / server) the architecture. Network teaching system design is the main function is to complete the network teaching requirements for teachers and students to provide safe, reliable and efficient teaching services.

In the cloud computing environment, the network teaching system provides the sharing of learning resources by the mode of the cloud service, and the teachers' electronic courseware and the teaching electronic resources in the network teaching system all share the resources of the cloud service. The resources of the network teaching system based on cloud computing can be used by their own teachers and students. They can also be shared with other teachers and students in colleges and universities to provide resource sharing service for educational information system. The network teaching system based on cloud computing can realize the sharing of teaching resources and avoid the repetition of teaching resources.

\subsection{The functions of all levels in cloud computing-based network teaching system platform}

The purpose of cloud computing network teaching system is to carry out longdistance education and students' independent learning, using cloud computing technology to establish teaching evaluation, teaching resource management and teaching management of three systems, cloud computing network teaching system, including cloud platform, cloud platform core application layer, Cloud platform operations management, cloud platform infrastructure layer. The main function of the presentation layer is the interface design of the platform. The interface provides teachers with a special function platform, including online Q \& A and teaching evaluation. It provides students with on-line course selection and online questioning, and provides communication between parents and schools. To facilitate parents in a timely manner to grasp the school's dynamic information for technical management personnel to provide security management and fault maintenance and management of functional services. The cloud platform core application layer is the core of the whole network platform with the computing network teaching system. At the application layer of the cloud platform, users can update and improve their own database and software library, and implement the teaching process at the core application layer of the cloud platform. Can be reflected, the teaching can be effectively managed. Cloud platform management functions are the same scheduling, billing management, system management and security management and other basic management functions, operational management functions, users can design and develop according to their own 
needs, both in software and technology Provided by a third party. Cloud platform infrastructure management capabilities are mainly statistical analysis of reports, application storage and billing, and developer identity authentication, development and testing capabilities, including AP interface and application performance testing, the basic framework capabilities include the scale query module, programming Interface function module, task scheduling function module.

\section{Conclusion}

In summary, the computer cloud technology can create a better future for Chinese network teaching, for the status quo of the application of cloud technology in the education industry in domestic, China should do more research on cloud technology and make efforts to train the corresponding cloud technical personnel and keep continuous innovation of the application of computer cloud technology. Only in this way can we truly provide the high quality guarantee for the network teaching in our country.

\section{References}

[1] Huang Shengli. Application and Development of Exploring Cloud Technology. Henan Education, 55(12), pp.68-70, 2011

[2] Lu Fei. Application of Virtual Cloud Technology in the Construction and Management of Computer Labs. Technical School, 8 (5), pp.87- 91, 2013

[3] Lin Pei, Explore the application and development of cloud computing, China's new technology and new products, 12(10), pp. 18- 20, 2012

[4] Sun Tao. The Application of Virtual Cloud Technology in the Construction and Management of Computer Lab. Journal of Daqing Normal University, 9(6), pp.58- 61, 2011

[5] Pang Weiwei. Brief Introduction of Computer Cloud Computing Technology. Computer CD - ROM Software and Application, 8(4), pp.85-87, 2014 